\title{
Wheat mutant MNR220 delays haustoria formation during leaf rust pathogenesis at the seedling stage
}

\author{
Authors: Mina Talajoor, Xiaojing Wang, Hongtao \\ Zhang, Peng Zhang, Sridhar Bhavani, Linda Tabe, \\ Evans Lagudah, and Li Huang
}

This is an Accepted Manuscript of an article published in Canadian Journal of Plant Pathology on September 2016, available online:

http://www.tandfonline.com/10.1080/07060661.2016.1205663

Talajoor, Mina, Xiaojing Wang, Hongtao Zhang, Peng Zhang, Sridhar Bhavani, Linda Tabe, Evans Lagudah, and Li Huang. "Wheat mutant MNR220 delays haustoria formation during leaf rust pathogenesis at the seedling stage." Canadian Journal of Plant Pathology 38, no. 3 (September 2016): 338-347. DOI: 10.1080/07060661.2016.1205663.

Made available through Montana State University's $\underline{\text { ScholarWorks }}$ scholarworks.montana.edu 


\title{
Wheat mutant MNR220 delays haustoria formation during leaf rust pathogenesis at the seedling stage
}

\author{
MINA TALAJOOR ${ }^{1 *}$, XIAOJING WANG ${ }^{1,2}$, HONGTAO ZHANG ${ }^{1}$, PENG ZHANG $^{3}$, SRIDHAR BHAVANI $^{4}$, \\ LINDA TABE ${ }^{5}$, EVANS LAGUDAH ${ }^{5}$ AND LI HUANG ${ }^{1}$ \\ ${ }^{1}$ Department of Plant Sciences and Plant Pathology, Montana State University, Bozeman, MT 59717-3150, USA \\ ${ }^{2}$ State Key Laboratory of Crop Stress Biology for Arid Areas, College of Life Sciences, Northwest A\&F University, Yangling, 712100 Shaanxi, \\ P.R. China \\ ${ }^{3}$ Plant Breeding Institute, The University of Sydney, Cobbitty, NSW 2570, Australia \\ ${ }^{4}$ International Maize and Wheat Improvement Center (CIMMYT), ICRAF House, United Nations Avenue, Gigiri, P.O. Box 1041, Village \\ Market 00621, Nairobi, Kenya \\ ${ }^{5}$ CSIRO Plant Industry, GPO Box 1600, Canberra, ACT 2601, Australia
}

\begin{abstract}
This study reports further characterization of the defence mechanism of an EMS-induced mutant (MNR220) that displays enhanced resistance to leaf rust, stem rust, stripe rust and powdery mildew diseases. The broad-spectrum resistance of the mutant was characterized by a microscopy study and additional race screenings of two rust pathogens. The mutant displayed less disease severity in response to all the races tested, when compared with the wild-type. The microscopy study of the pathogenesis of a leaf rust race PBJJG on the mutant revealed that the resistance was first evident at the pre-haustorial stage; formation of haustoria was significantly delayed or inhibited in the mutant compared with the wild-type. The mutant displayed microscopic level of cell death even in the absence of any pathogens. These findings suggest that MNR220 mediates a spontaneous cell death that delays the infection process by delaying haustoria formation of the pathogen.
\end{abstract}

Keywords: biotrophic fungi, cell death, disease development, haustorium, rust resistance, wheat 


\section{Introduction}

Haustoria are specialized cellular structures formed by both biotrophic fungi and oomycetes during pathogenesis. This structure is formed and established inside the plant cells and is the site for the pathogens to deliver effectors to suppress host defence response (Bozkurt et al. 2011) and to acquire nutrients from the host cells (Hall \& Williams 2000; Voegele \& Mendgen 2003). Therefore, establishment of haustoria in plant cells is a prerequisite for successful colonization of a plant host by biotrophic pathogens.

Puccinia triticina (Pt), P. graminis f. sp. tritici (Pgt), P. striiformis f. sp. tritici (Pst) and Blumeria graminis f. $\mathrm{sp}$. tritici (Bgt), the pathogens that cause leaf, stem and stripe rusts and powdery mildew diseases in wheat, respectively, are all biotrophs that only infect living cells, pilfering host nutrients via haustoria (Dodds et al. 2004). Although the mechanisms of nutrient assimilation using haustoria are similar between these four wheat pathogens, there are differences in their methods of invading host cells. The urediniospores of the rusts germinate and enter the plant cells through stomatal openings, giving rise to intercellular hyphae that ultimately invaginate mesophyll cells forming haustoria (Mendgen \& Hahn 2002). In contrast, powdery mildew conidiospores germinate to produce appressoria that penetrate the leaf through the cuticle and subsequently invaginate epidermal cells exclusively (Huckelhoven 2005). In this study, we focused on the mechanism of MNR220 resistance to leaf rust.

MNR220 is an ethyl methanesulfonate (EMS)-mutagenesis-derived mutant from the white spring wheat variety 'Alpowa'. The mutant showed enhanced resistance to $P t$, Pgt, Pst and Bgt (Campbell et al. 2012). We hypothesized that the mutant has a defence mechanism that is effective against biotrophic pathogens. MNR220 exhibited reduced disease severity at the seedling stage during early infection, featured as resistance to pathogen invasion up to 18 days post inoculation (dpi), then the resistance became insignificant, and was as susceptible as the susceptible wild-type after 22 dpi (Campbell et al. 2012). The objective of this study was to investigate the defence mechanism of the mutant against leaf rust. We chose to characterize the histological response of MNR220 to leaf rust infection to reveal the steps that reduce the rust severity in planta. The observations suggest that MNR220 mediates a pre-haustorial defence response to leaf rust at the seedling stage.

\section{Materials and methods}

\section{Plant materials}

Spring wheat cultivar 'Alpowa' (PI 566596) was obtained from the USDA National Plant Germplasm System
(NPGS). MNR220 was a mutant of 'Alpowa' derived via EMS mutagenesis. Development of the EMS population was described in Feiz et al. (2009). The resistant individual MNR220 was identified at $\mathrm{M}_{4}$ generation and subsequently selfed to $M_{6}$ (Campbell et al. 2012). For this study, all the MNR220 seeds were from the $\mathrm{M}_{6: 7}$ generation of a single resistant MNR220 plant.

\section{Pathogens}

The Pt PBJJG was used in the microscopic study. The urediniospores were increased on 'Alpowa' from a single pustule of the PRTUS6 provided by Dr Robert Bowden (USDA-ARS, Manhattan, KS). The race identification was according to the North American Nomenclature System (Long \& Kolmer 1989; Campbell et al. 2012) based on the infection types on the leaf rust differential sets. The $P t$ races of PRTUS6, PRTUS50, PRTUS61, LR2010-2.1 and PRTUS54 were maintained at USDAARS, Manhattan, KS. The $P t$ races TFBG and TFBJ, and Pst races $415\left(104 \mathrm{E} 137 \mathrm{~A}^{-}\right), 444\left(110 \mathrm{E} 143 \mathrm{~A}^{+}\right), 572$ $\left(134 \mathrm{E}^{16 ~ \mathrm{~A}^{+}}\right)$and $602\left(134 \mathrm{E}^{+} 6^{+} \mathrm{Jackie}^{+}\right)$were maintained at the Plant Breeding Institute, University of Sydney.

\section{Plant growth conditions}

For $P t$ race specificity screening and histology studies, seeds were planted in 6-pack seed trays (each cell $5 \mathrm{~cm} \times 8 \mathrm{~cm} \times 8 \mathrm{~cm}$ ) with two seeds per cell in Sunshine Mix \#1 (Sun Gro Horticulture, Vancouver, BC, Canada). Every 12 of the 6-pack seed trays were then placed in a $3 \mathrm{~cm} \times 35 \mathrm{~cm} \times 40 \mathrm{~cm}$ tray and watered from the bottom through the big tray. Individuals were grown to 1-3 leaf stage for seedling studies. The plants were kept in a greenhouse at the MSU-PGC with an average daytime temperature of $24^{\circ} \mathrm{C}$ and a night-time temperature of $19^{\circ} \mathrm{C}$.

To create a microbe-free environment for the study, the MNR220 and 'Alpowa' were grown in plant tissue culture medium. The recipe is as following: $4.44 \mathrm{~g}$ Murashige \& Skoog basal medium plus Gamborg vitamins (Phytotechnology Laboratories, LLC, Kansas City, KS), $20 \mathrm{~g}$ sucrose, $1 \mathrm{~mL}$ plant preservative mixture (PPM) (Phytotechnology Laboratories) and $0.1 \mathrm{~mL}$ kinetin $(0.04 \mathrm{~g}$ kinetin in $100 \mathrm{~mL}$ of $2 \% \mathrm{NaOH})$ in $800 \mathrm{~mL}$ $\mathrm{ddH}_{2} \mathrm{O}$. The medium was adjusted to $\mathrm{pH} 5.7$ with $2 \%$ $\mathrm{NaOH}$, and then $2 \mathrm{~g}$ Phytagel was added and $\mathrm{ddH}_{2} \mathrm{O}$ to bring the volume to $1 \mathrm{~L}$. The solution was autoclaved for $40 \mathrm{~min}$ at $121^{\circ} \mathrm{C}$. Aliquots of $30 \mathrm{~mL}$ were dispensed into glass tubes in a laminar flow hood. 
Twenty seeds per line were treated with $10 \%$ bleach for $2 \mathrm{~min}$ and washed in running water for $10 \mathrm{~min}$ before being placed onto sterilized basic growth medium with one seed per tube. The plants were kept in a growth chamber with an average day/night temperature of $24^{\circ}$ $\mathrm{C} / 19^{\circ} \mathrm{C}$ under a $16-\mathrm{h}$ photoperiod.

\section{Pathogen inoculation}

For leaf rust assay, seedlings were inoculated with urediniospores at the 1.5-2-leaf stage. A video protocol detailing this process can be accessed at https://vimeo.com/ 48605764. Urediniospores were mixed in Soltrol 170 Isoparaffin (Chempoint, Bellevue, WA) at a concentration of $5 \mathrm{mg} \mathrm{mL}$. The suspension was sprayed onto the leaves using a Badger 350 airbrush gun and Propel propellant (Badger Air-Brush Company, Franklin Park, IL). The inoculated seedlings were then placed in a Percival I-60D dew chamber (Percival Scientific Inc., Perry, IA) with dew formation and an ambient air temperature of $15-17^{\circ} \mathrm{C}$. After $24 \mathrm{~h}$ of incubation, the inoculated plants were placed back in the growth chamber or greenhouse.

Plant materials for assessing stripe rust responses were sown in $10-\mathrm{cm}$ pots filled with a pine bark and sand potting mix. Prior to sowing, pots were fertilized with the complete fertilizer, Aquasol ${ }^{\circledR}$. Approximately 7 days later, after seedling emergence, pots were fertilized with urea. Seedlings were grown in the glasshouse at $16-20^{\circ} \mathrm{C}$ and inoculated when they were at the 1.5-2 leaf stage. They were inoculated with a urediniospore suspension in light mineral oil and incubated in humidity chambers at $11 \pm 2^{\circ} \mathrm{C}$ for $24 \mathrm{~h}$. Seedlings were then moved to a greenhouse room with a temperature of $24 / 17^{\circ} \mathrm{C}$ (day/ night). Infection types (ITs) were scored at 12-16 days after inoculation according to a $0-4$ scale, where 0 indicates no visible symptoms and 4 indicates complete susceptibility (McIntosh et al. 1995).

\section{Tissue sampling and staining for microscopic observation}

Ten individual plants per line were inoculated with $P t$ PBJJG. Three replications were conducted and inoculated on three different days. In each inoculation, MNR220 and the wild-type 'Alpowa' as a control were included. Two plants were randomly selected from each line at 1 day post inoculation (dpi), 2 dpi and 3 dpi. The primary leaves were sampled, and $1.5 \mathrm{~cm}$ of both the tip and the base of the leaf were removed. The remainder was cut into eight equal pieces $(\sim 1-1.5 \mathrm{~cm}$ each), and each segment was placed directly into a $2-\mathrm{mL}$ gasket-sealed screw-cap tube filled with $1.7 \mathrm{~mL}$ of alcoholic lactophenol-trypan blue (1 part of lactophenol-trypan blue to 2 parts of $95 \%$ ethanol). The clearing/staining process was adapted from Shipton \& Brown (1962). Lactophenoltrypan blue was prepared as follows: $10 \mathrm{~mL}$ buffer-saturated phenol, $10 \mathrm{~mL}$ glycerol, $10 \mathrm{~mL}$ lactic acid, $0.02 \mathrm{~g}$ trypan blue (C.I. No. 23850, Sigma Chemical Co., St.

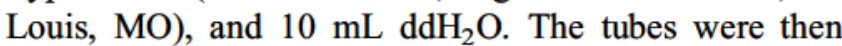
capped tightly and placed in a preheated water bath set to $90^{\circ} \mathrm{C}$ until the leaf sections were translucent and stained medium blue (about 15-20 min). Each tube was inverted at least once during this step. The tubes were then removed from the water bath and placed in the dark at room temperature to let the staining process continue. The samples were kept in this condition for up to 2 weeks before being examined.

Before examination, leaf segments were destained in a chloral hydrate solution $(5 \mathrm{~g} / 2 \mathrm{~mL})$ for $1-2 \mathrm{~h}$. The leaf samples were then placed in Visikol (Phytosys LLC, New Brunswick, NJ) to clear overnight. Samples were mounted in Visikol and examined using a light microscope (Leica DM750, Wetzlar, Germany). Images were captured using a Leica HD digital camera.

For callose deposition tests, aniline blue staining was used as described by Luna et al. (2011). Leaf segments were collected and incubated for at least $24 \mathrm{~h}$ in $95-100 \%$ ethanol until all tissues were transparent. Cleared leaf segments were washed in $0.07 \mathrm{M}$ phosphate buffer $(\mathrm{pH}$ 9), and were incubated for 1-2 h with $0.07 \mathrm{M}$ phosphate buffer containing $0.01 \%$ aniline-blue (Sigma, St. Louis, $\mathrm{MO})$ prior to microscopic analysis.

For fluorescence microscope observations, leaf segments were cleared with $1: 1$ of $100 \%$ ethanol and acetic acid for at least $24 \mathrm{~h}$ and observed under a Nikon Eclipse 80i (Upright) Operation using X-cite 120 illuminator, Reflector Cube Positions 3FITC (Melville, NY).

\section{Microscopic observations}

The adaxial surface of each leaf sample was examined by light microscopy. Intact plant cells were stained light blue while fungal hyphae were stained dark blue. Plant cells that were stained dark blue were considered as necrotic.

Once calibrated with a stage micrometer, all measurements were conducted using the live measurement tool in the Leica computer software LAS v3.0. The two outermost rows of stomata on each side of the leaf edge were not studied. An infection site was defined as a spore that had successfully formed an appressorium and substomatal vesicle in the substomatal cavity beneath the guard cells. Up to 15 randomly chosen infection sites that had successfully formed a substomatal vesicle were investigated per leaf segment. Infection sites where two or more appressoria had formed over a single stoma were not 
considered. The presence of infection hyphae and the number of hyphal tips were recorded. The maximum hyphal distance was calculated for each site by measuring the distance from the substomatal vesicle to the farthest hyphal tip. Infection sites that formed a substomatal vesicle and had more than one hyphal tip or a haustorium at 2 or 3 dpi were considered established and were included in the studies.

\section{Statistical analysis}

Student's $t$-tests were performed to test whether the mutant and wild-type are different in the latency period, formation and the development of haustoria. The P-values were calculated based on two-tailed distribution and twosample equal variance. Logistic regression analysis was performed to confirm the $t$-test results.

\section{Results}

Broad spectrum resistance of MNR220 at seedling stage

MNR220 was identified from the $\mathrm{M}_{4}$ generation of a mutagenized 'Alpowa' population due to its resistance to $P t$ isolate PBJJG. The mutant was tested with three $P t$ races, four Pst races and $13 P g t$ races in a previous study (Campbell et al. 2012). In this study, further tests were conducted to investigate the spectrum of resistance in MNR220 using additional pathogen races including foreign isolates of Pt and Pst from Australia. In general, MNR220 showed less disease severity to each of the races compared with the wild-type 'Alpowa', although the levels of resistance varied among different races (Table 1). Among the Pt races, MNR220 was resistant to three races, PRTUS50, LR2012-2.1 and PRTUS54, to which the wild-type was susceptible (Table 1). MNR220 was susceptible to $P t$ race PRTUS61 with an IT of 3, but was less susceptible to this race than Alpowa (IT $3^{+}$).

Both MNR220 and 'Alpowa' showed a certain level of resistance to the four Australian Pst races. However, MNR220 had smaller or fewer pustules than 'Alpowa', giving a more resistant score for all races except isolate 415 , to which the two genotypes showed comparable levels of resistance (Table 1).

Leaf rust pathogenesis at the seedling stage of MNR220 was unique. The latency period, defined as hours post inoculation to the appearance of the first pustule, was not different between MNR220 and 'Alpowa' under the $24-26^{\circ} \mathrm{C} / 16-18^{\circ} \mathrm{C}$ (day/night) temperature regime. In the first replication, pustules were counted with the naked eye. The latency period was calculated as an average of $190 \mathrm{~h}$ for 'Alpowa' and $191 \mathrm{~h}$ for MNR220. For the second
Table 1. Infection responses of 'Alpowa' and MNR220 seedlings to races of Puccinia spp.

\begin{tabular}{llcl}
\hline \hline & & \multicolumn{2}{c}{ Infection type } \\
\cline { 3 - 4 } Pathogen & \multicolumn{1}{c}{ Race } & 'Alpowa' & MNR220 \\
\hline$P t$ & PBJJG $^{\mathrm{a}}$ & $3 \sim 3^{+}$ & $1^{-} \sim 2^{+} \mathrm{C}$ \\
& TFBG $^{\mathrm{b}}$ & $3^{+}$ & $2^{+} \mathrm{C}$ \\
& TFBJ $^{\mathrm{b}}$ & $3^{+}$ & $2 \mathrm{C}^{+} \mathrm{N}^{+}$ \\
& PRTUS6 $^{\mathrm{c}}$ & 3 & $;$ \\
& PRTUS50 $^{\mathrm{c}}$ & 3 & 1 \\
& PRTUS61 $^{\mathrm{c}}$ & $3^{+}$ & 3 \\
& LR2010-2.1 $^{\mathrm{c}}$ & $3^{+}$ & 2 \\
& PRTUS54 $^{\mathrm{c}}$ & 3 & 1 \\
& $415^{\mathrm{b}}$ & $3 \mathrm{C}$ & $3^{-} \mathrm{C}$ \\
& $572^{\mathrm{b}}$ & $3^{-} \mathrm{C}$ & $2 \mathrm{NN}$ \\
& $602^{\mathrm{b}}$ & $3 \mathrm{C}$ & $2^{-} \mathrm{C}$ \\
& $444^{\mathrm{b}}$ & $3 \mathrm{C}$ & $23^{-} \mathrm{C}$ \\
\hline \hline
\end{tabular}

${ }^{a}$ Disease assessment conducted in the Plant Growth Center at Montana State University.

${ }^{\mathrm{b}}$ Disease assessment conducted at the University of Sydney.

${ }^{c}$ Disease assessment conducted at USDA-ARS at Kansas State University. Pathogens used for infection type assessment were Puccinia triticina $(P t)$ and $P$. striiformis f. sp. tritici (Pst).

For rust disease assessment, a 0 (immune) 4 (highest susceptible) infection type scale was used as described in McIntosh et al. (1995). Infection type classes are further qualified with $\mathrm{a}+$ (more than average) or a - (less than average). A semicolon (;) indicates the presence of hypersensitive flecks. C, chlorosis; N, necrosis; ' $\sim$ ' indicates a range of infection types observed among different plants.

replication, erupted pustules could be seen more clearly with a hand magnifying glass. The latency period was $164 \mathrm{~h}$ for 'Alpowa' and $162 \mathrm{~h}$ for MNR220, respectively. A P-value of 0.95 based on the statistical analysis of the two replicates suggested that MNR220 and 'Alpowa' had a similar latency period. However, on the same inoculated leaves, the density of pustules, measured by the number of pustules per $\mathrm{cm}^{2}$ leaf surface, was significantly less in MNR220 at 8 dpi than that at $22 \mathrm{dpi}$. The pustule density in 'Alpowa' was little changed during the same time period. More pustules started to appear on the same inoculated leaves of MNR220 after 12 dpi, the severity of the disease was gradually increased, making the difference between the mutant and 'Alpowa' insignificant after 22 dpi as shown in the previous publication (Campbell et al. 2012).

\section{Microscopic characterization of leaf rust disease development in MNR220}

The parameters investigated included urediniospore germination rate, germ tube elongation rate measured by the tube length overnight, the number of penetration/infection sites and infection structure differentiation/haustorial formation. In this study, we define infection sites as the sites with the presence of appressoria. From the first replicate, 
there was little difference in spore germination rate on MNR220 and 'Alpowa'; both were above $90 \%$. The germ tubes all reached stomata after overnight incubation. The percentage of infection sites that had formed infection hyphae were above $80 \%$ at $1 \mathrm{dpi}$ and about $90 \%$ at 2 dpi in both genotypes (Table 2). The number of hyphal tips per infection site between the mutant and the wildtype were the same (Table 2) and were less variable among different samples. The maximal hyphal lengths were highly variable among plant samples, but the differences were insignificant between the wild-type and MNR220 (Table 2). The number of sites with infection hyphae and at least one haustorium was counted. The haustoria were categorized into young (Fig. 1a), intermediate (Fig. 1b) and mature (Fig. 1c) types. In MNR220, there was a lower haustorium forming rate at $1 \mathrm{dpi}$ and $2 \mathrm{dpi}$ (Table 3). An average of $85 \%$ of infection sites on 'Alpowa' formed at least one haustorium at $1 \mathrm{dpi}$ and $89 \%$ at 2 dpi. In contrast, $49.5 \%$ of infection sites on MNR220 had developed a haustorium at $1 \mathrm{dpi}$ and $45 \%$ at 2 dpi (Table 3 ).

At $1 \mathrm{dpi}$, neither the wild-type nor MNR220 had more than one haustorium per infection site, and they were all classified as young (Fig. 1a) or intermediate type (Fig. 1b). Although the sites with initial forming haustoria appeared to have a significant difference between the

Table 2. Infection progress of Pt race PBJJG in seedlings of the wild-type 'Alpowa' and MNR220.

\begin{tabular}{|c|c|c|c|c|c|c|}
\hline & \multicolumn{2}{|c|}{$1 \mathrm{dpi}$} & \multicolumn{2}{|c|}{2 dpi } & \multicolumn{2}{|c|}{3 dpi } \\
\hline Sites observed & 43 & 73 & 91 & 176 & 35 & 68 \\
\hline Sites with infection hyphae (\%) & 81.4 & 87.7 & 95.6 & 89.8 & & \\
\hline Average \# hyphal tips & 1.7 & 2.0 & 8.6 & 8.6 & & \\
\hline Mean max hyphal distance $(\mu \mathrm{m})$ & $48.7 \pm 21.0$ & $47.2 \pm 19.2$ & $80.2 \pm 32.9$ & $74.5 \pm 32.6$ & $132.8 \pm 47.0$ & $130.5 \pm 63.5$ \\
\hline
\end{tabular}

Primary leaves of 'Alpowa' and MNR220 were collected at 1, 2 and 3 days post-inoculation (dpi) and processed for histological observations.
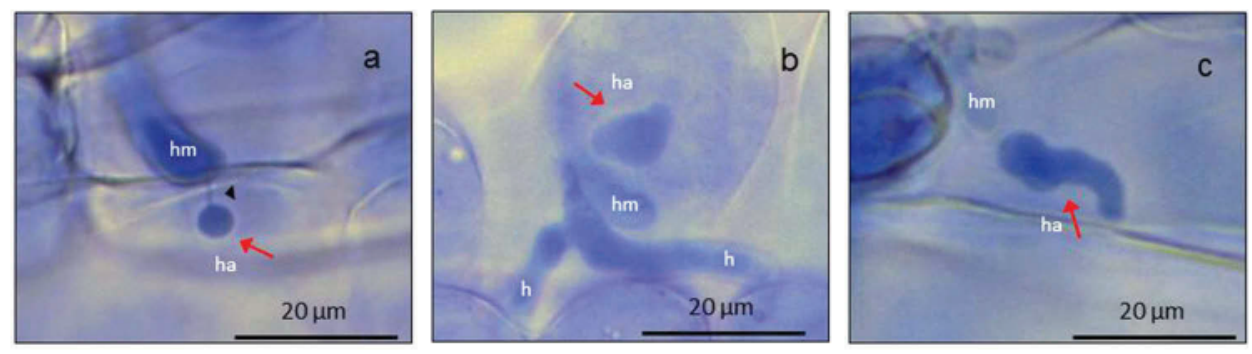

MNR220

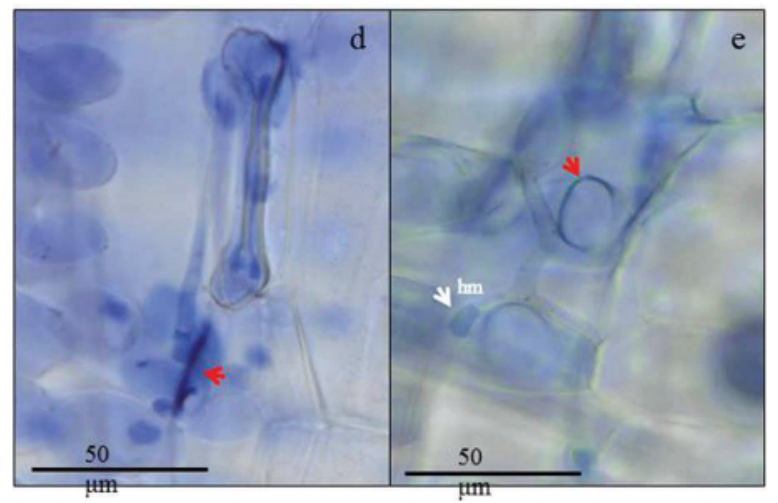

Fig. 1 (Colour online) a, Young, round haustorium (ha). The haustorial neck (arrowhead) connecting to the haustoria mother cell (hm) is clearly visible. b, Intermediate haustorium characterized by oblong shape and lobes beginning to form. Two additional hyphal tips (h) have formed. c, Mature haustorium with distinct lobe protruding to the right. d, The primary infection hyphae did not form a haustorial mother cell and is in contact with the host cell where the area is darkly stained with trypan blue (a red arrow). e,) The first attempt of haustoria formation was unsuccessful where the cell periphery is dark blue (a red arrow). The hyphae continued to grow, found a suitable cell and formed a haustorial mother cell (a white arrow). 
Table 3. Haustoria formation in seedlings of 'Alpowa' and MNR220 infected with Pt race PBJJG.

\begin{tabular}{|c|c|c|c|c|c|c|c|c|c|c|c|}
\hline \multicolumn{12}{|c|}{1 dpi } \\
\hline & 1 rep & 2 rep & 3 rep & Mean & SD & 1 rep & 2 rep & 3 rep & Mean & SD & p-value \\
\hline Sites observed & 43 & 50 & 50 & & & 73 & 50 & 50 & & & \\
\hline Sites with haustoria (\%) & 88 & 88 & 80 & 85.3 & 4.6 & 47 & 44 & 58 & $49.5^{*}$ & 7.5 & 0.002 \\
\hline Ratio of Y haustoria & 79 & 64 & 40 & 61.0 & 19.7 & 85 & 82 & 66 & 77.5 & 10.6 & 0.264 \\
\hline \multirow{3}{*}{ Ratio of $\mathrm{M}$ haustoria } & \multicolumn{10}{|c|}{2 dpi } & \\
\hline & \multicolumn{5}{|c|}{ Alpowa } & \multicolumn{5}{|c|}{ MNR220 } & \multirow[b]{2}{*}{$p$-value } \\
\hline & 1 rep & 2 rep & 3 rep & Mean & SD & 1 rep & 2 rep & 3 rep & Mean & SD & \\
\hline Ratio of $M$ haustoria & 24 & 18 & 19 & 20.3 & 3.1 & 10 & 17 & 9 & 17.0 & 8.0 & 0.056 \\
\hline
\end{tabular}

Y, Young; I, Intermediate; M, Mature haustoria. The percentage of infection sites with haustoria was calculated from the number of sites that had formed infection hyphae. The ratio of haustoria maturity was calculated as the percentage of each type of haustoria out of the total number of haustoria and was rounded to the nearest whole number. * indicates a significant difference between 'Alpowa' and MNR220 with a P-value $<0.05$.

mutant and the wild-type during $\sim 1-2 \mathrm{dpi}$, the speed of maturity of the haustoria in the two lines was similar. The ratio of each category of haustoria in the mutant and the wild-type did not show a significant difference (Table 3). The t-test results were confirmed with logistic regression analysis (results not shown).

It was often observed that the infecting hyphae interacted with MNR220 cells resulting in no haustoria but with increased trypan blue staining (Fig. 1d). The infection site in Fig. 1d showed an infection hypha which failed to form a haustorium in the first encountered cell, which is stained darkly along the cell wall. The hypha continued to grow, and a haustorial mother cell was evident after the hypha reached a suitable cell (Fig. 1e). Therefore, the percentage of sites with stain retention and collapsed cells in both the mutant and the wild-type at 1 , 2 and 3 dpi was calculated (Table 4). From 1 to 3 dpi, the mutant showed a higher ratio of stain retentions and collapsed cells than the wild-type.

Additionally, even without rust inoculation, it was observed that the periphery of some epidermal and mesophyll cells of MNR220 were stained a darker blue compared with the cells in the wild-type that were stained a uniform light blue. Collapsed protoplasts were present in MNR220, which were stained dark blue with trypan blue, indicating cellular necrosis (data not shown). A greater proportion of cells in MNR220 with borders stained darker than in the wild-type. They varied in the pattern of stain retention; some cells were equally stained around the periphery of the cell, while others were darkly stained in a focused area (data not shown).

\section{Spontaneous cell death associated with MNR220}

To investigate whether the stain retention was trigged by infection, primary leaves from the plants grown in sterile conditions were stained. MNR220 consistently showed patches of dark blue-stained cells with varying sizes across the leaf (Fig. 2a), which were absent in the wildtype (Fig. $2 b$ ). In a zoom-in view, a dark blue patch included dark stained collapsed cells (arrows) and noncollapsed dark-stained cell peripheries (arrowhead), whereas 'Alpowa' showed uniform light blue background staining (Fig. 2b). To investigate whether the altered cell wall deposition was associated with the dark stained peripheries around the non-collapsed cells, aniline blue was used to stain to check callose deposition in MNR220 without rust inoculation. No differences in callose staining between MNR220 and the wild-type were found (data not shown).

Trypan blue usually stains dead cells dark blue. To confirm whether the stain retention in MNR220 was due to cell death, leaves of 'Alpowa' and MNR220 were examined under a epifluorescence microscope for autofluorescence. Again, to exclude the possibility that any microbes in the greenhouse environment could trigger 
Table 4. Infection sites with stain retention and collapsed cells in seedlings of the wild-type 'Alpowa' and MNR220.

\begin{tabular}{|c|c|c|c|c|c|c|c|c|c|c|c|}
\hline \multicolumn{12}{|c|}{1 dpi } \\
\hline & \multicolumn{5}{|c|}{ Alpowa } & \multicolumn{5}{|c|}{ MNR220 } & \multirow[b]{2}{*}{ p-value } \\
\hline & 1 rep & 2 rep & 3 rep & Mean & SD & 1 rep & 2 rep & 3 rep & Mean & SD & \\
\hline Sites observed & 43 & 50 & 50 & & & 73 & 50 & 50 & & & \\
\hline Sites with stain retention (\%) & 14 & 10 & 2 & 8.7 & 6.1 & 85 & 50 & 60 & $65.0 *$ & 18.0 & 0.007 \\
\hline \multirow[t]{4}{*}{ Sites with collapsed cells (\%) } & 5 & 4 & 0 & 3 & 2.6 & 41 & 38 & 32 & $37.0^{\text {** }}$ & 4.6 & 0.0004 \\
\hline & \multicolumn{10}{|c|}{2 dpi } & \\
\hline & \multicolumn{5}{|c|}{ Alpowa } & \multicolumn{5}{|c|}{ MNR220 } & \\
\hline & 1 rep & 2 rep & 3 rep & Mean & SD & 1 rep & 2 rep & 3 rep & Mean & SD & P-value \\
\hline Sites observed & 91 & 50 & 50 & & & 176 & 50 & 50 & & & \\
\hline Sites with stain retention (\%) & 12 & 8 & 4 & 8.0 & 4.0 & 61 & 70 & 66 & $65.7^{* *}$ & 4.5 & 0.0001 \\
\hline \multirow[t]{4}{*}{ Sites with collapsed cells (\%) } & 5 & 2 & 2 & 3.0 & 1.7 & 32 & 40 & 42 & $38.0^{\text {** }}$ & 2.0 & 0.0004 \\
\hline & \multicolumn{10}{|c|}{3 dpi } & \\
\hline & \multicolumn{5}{|c|}{ Alpowa } & \multicolumn{5}{|c|}{ MNR220 } & \\
\hline & 1 rep & 2 rep & 3 rep & Mean & SD & 1 rep & 2 rep & 3 rep & Mean & SD & p-value \\
\hline Sites observed & 35 & 50 & 50 & & & 68 & 50 & 50 & & & \\
\hline Sites with stain retention (\%) & 11 & 4 & 10 & 8.3 & 3.8 & 97 & 76 & 52 & $75.0 *$ & 22.5 & 0.007 \\
\hline Sites with collapsed cells (\%) & 6 & 0 & 2 & 2.0 & 3.1 & 85 & 38 & 22 & 48.3 & 32.7 & 0.073 \\
\hline
\end{tabular}

'Alpowa' and MNR220 were inoculated with $P t$ race PBJJG. Primary leaves were collected at 1, 2, and 3 days post-inoculation (dpi) and processed for histological observations.

Stain retention and necrosis are only for cells associated with infection sites near them $\left({ }^{*}\right)$ and $\left({ }^{* *}\right)$ indicates a significant difference between 'Alpowa' and MNR220 at that particular dpi with a P-value $<0.05$ and 0.001 , respectively.

MNR220

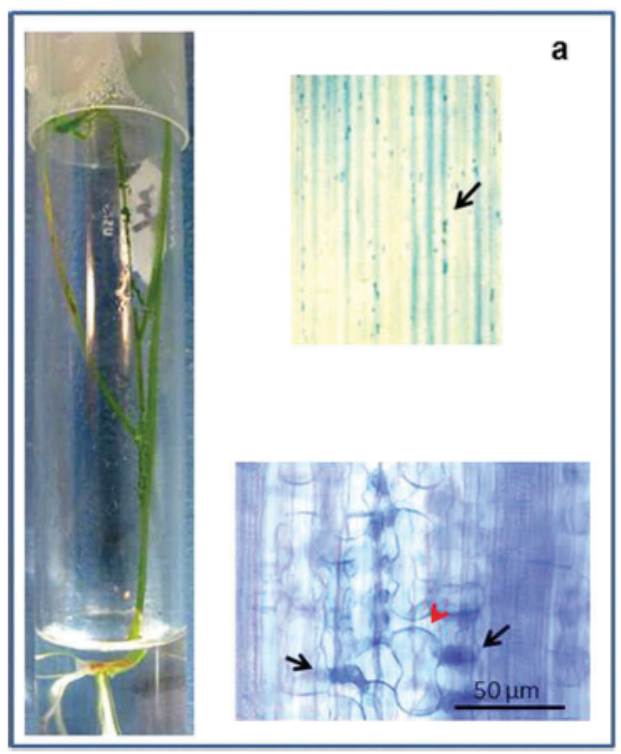

Alpowa

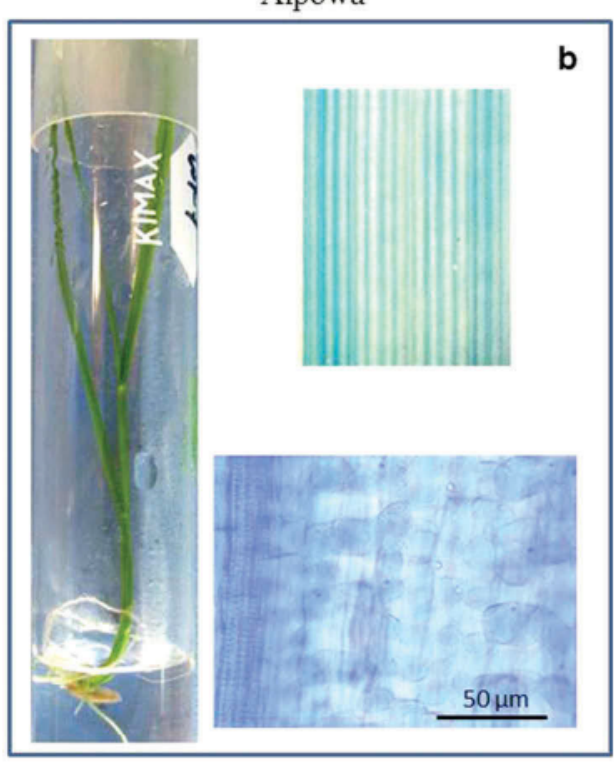

Fig. 2 (Colour online) Uninoculated primary leaves of MNR220 and 'Alpowa' grown in sterile conditions at three leaf stage showing different stain retention patterns. a, MNR220 seedling in sterilized culture (left), a leaf segment after trypan blue staining (upper right) shows scattered blue stain retention (arrow) and a zoom-in view of a dark stained area (lower right) shows collapsed cells (black arrows) and dark stained cell periphery (red arrowhead). b, The wild-type 'Alpowa' seedling in sterilized culture (left), a leaf segment after trypan blue staining (upper right) shows an evenly light stained pattern and a zoom-in view of an area (lower right). 

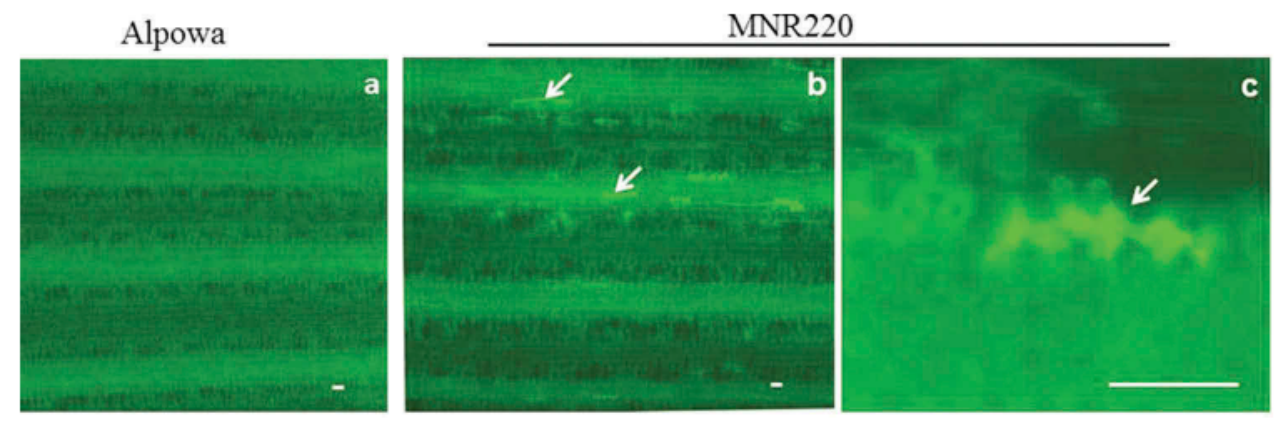

Fig. 3 (Colour online) Histological observation of 'Alpowa' and MNR220 leaves from plants grown in a sterile condition under an epifluorescence microscope. a, 'Alpowa' first leaf at three leaf stage, b, MNR220 first leaf at three leaf stage shows scattered auto-fluorescence (arrows), c, A zoom-in view of MNR220 first leaf shows auto-fluorescent mesophyll cell (arrow). Bars $=50 \mu \mathrm{m}$.

cell death in MNR220, the examined leaves were from plants grown in a sterile tissue culture condition (Fig. $2 a$, $2 b$ ). Under epifluorescence microscopy, no auto-fluorescence appeared in 'Alpowa' seedling leaves (Fig. 3a); however, a strong auto-fluorescence of mesophyll cells was observed on MNR220 seedling leaves (Fig. 3b, 3c), indicating cell death. The epifluorescence microscopic observation is consistent with the trypan blue staining, indicating spontaneous cell death in MNR220 prior to pathogen infection.

\section{Discussion}

In this study, we observed a lower frequency of haustorium formation in MNR220 relative to the wild-type 'Alpowa' at 1 and 2 dpi (Table 3). It appeared that the formation of the first haustorium in the mutant was either delayed or inhibited. At $1 \mathrm{dpi}$, the maximum number of haustoria per infection site was one in both 'Alpowa' and MNR220. The differences in the percentage of sites with the presence of haustoria between the two lines at $\sim 1-$ 2 dpi suggested that MNR220 had the ability to inhibit the establishment of primary haustoria. From the sites with haustoria, no difference was detected in the period of time of haustorial maturity between the two lines. This observation suggested that there were site-specific differences in MNR220 regarding the ability to thwart infection attempts. Once a young haustorium was formed, the growth rates in the wild-type and MNR220 were similar (Table 3). Because the pustule density in the wild-type did not increase over time, and the pustules in MNR220 did not surround an early-formed pustule, which is a typical sign of secondary infection, the reduced disease severity in MNR220 must be stimulated by the challenge of the primary haustoria. This observation may explain the lower density of pustules on MNR220 seedling leaves before $12 \mathrm{dpi}$, and might also be the reason why the plant showed resistance to all the tested biotrophic haustoriumforming pathogens. If the first attempt to form a haustorium is unsuccessful, the infecting hyphae will continue to seek other cells to attack. Thus it takes a longer time for the pathogen to establish a haustorium if it did not succeed the first time. Without the formation of a haustorium, the spore would die from a lack of nutrients. Host defence mechanisms delaying or inhibiting haustorium formation have been extensively studied (Niks 1983, 1986; Wolter et al. 1993; Rubiales \& Niks 1995). Rubiales \& Niks (1995) observed that the non-hypersensitive resistance conferred by $L r 34$ in wheat was the result of reduced rates of haustoria formation during early infection. Failure of haustorial formation was reported to be the mechanism of partial resistance to powdery mildew in barley (Niks 1983, 1986).

Poor haustorium formation was due to a low rate of intercellular hyphal growth in Lr34-containing lines (Rubiales \& Niks 1995). However, we did not detect any difference in intercellular hyphal growth and callose deposition between MNR220 and the wild-type, indicating that a low rate of hyphal growth or cell wall reinforcement were not responsible for the poor haustorium formation in this case. The unsuccessful formation of a haustorium in MNR220 was always associated with dark stained cell periphery (Fig. $1 d, 1 e$ ). The retention of stain could be a harbinger of impending necrosis. Trypan blue is a stain by virtue of dye exclusion. The dye molecule is relatively large and is not transported across the cell membrane. When a cell undergoes necrosis (or apoptosis), the membrane becomes compromised so that the dye molecule can penetrate and stain nitrogenous compounds in the cytoplasm (Tennant 1964). The fact that autofluorescence and trypan blue-stained collapsed cells were observed in leaves of MNR220 grown in a microbe-free condition suggested spontaneous cell death. Sporadically distributed dead cells may impose 
difficulty to a biotrophic pathogen to find a living cell to establish a primary haustorium.

Wolter et al. (1993) found that the mlo gene was responsible for spontaneous cell wall apposition formations in epidermal cells regardless of the presence of a pathogen, thereby contributing to powdery mildew resistance. It was also responsible for spontaneous chlorosis and necrosis of older leaves in the absence of a pathogen (Huckelhoven 2005). Rapid death of host plant cells at the infection sites is a means of plant self-defence to microbial pathogens (Stakman 1915; Klement 1963; Klement \& Goodman 1967; Shirasu \& Schulze-Lefert 2000 ), especially to biotrophs that only survive and reproduce in living cells. This process is under intrinsic genetic control. We observed a degree of spontaneous cell death in MNR220 independent of any infection, suggesting a gene regulating cell death was mutated in MNR220. So far, five genes, including barley mlo (Büschges et al. 1997), maize lls1 (Dietrich et al. 1994; Gray et al. 1997), Arabidopsis $l s d l$ (Dietrich et al. 1997), edrl (Frye et al. 2001) and wheat TaAbcl (Wang et al. 2013), are known to be involved in cell death regulation. None of the wheat homologues of these five genes have been mapped to the chromosome $2 \mathrm{~B}$ short arm where the MNR220 gene is located (Campbell et al. 2012); thus we believe that MNR220 represents a new gene and that cloning of MNR220 will enrich our knowledge on plant cell death regulation.

At the seedling stage, the MNR220 locus confers enhanced resistance to multiple races of leaf, stem and stripe rusts, as well as to powdery mildew, compared with the wild-type 'Alpowa' (Campbell et al. 2012). However, the level of resistance to various fungal pathogens did appear to have some race-specificity. A perplexing result is the loss of seedling resistance to leaf rust race PRTUS61 and stripe rust isolate 415 in mutant MNR220 compared with the wild-type, which is similar to the findings on barley mlo resistance lines (Lyngkjaer et al. 1995). Barley mlo-resistant lines also have spontaneous cell death and confer broad-spectrum resistance to powdery mildew. However, Lyngkjaer et al. (1995) found that a Japanese powdery mildew isolate can successfully infect mlo resistant lines. Based on our observations, the different infection types of MNR220 to different $P t$ races happened after $10 \mathrm{dpi}$, and all the tested races had low sporulation at early time points, and thereafter some races started to produce more pustules. We speculate that $P t$ races have a different ability to endure starvation and only those that can survive longer without nutrients would find a suitable cell for haustorium formation.

\section{Acknowledgements}

We thank Jesse Poland (USDA-ARS, Kansas State University, Manhattan, KS 66506, USA) for helping with several leaf rust tests and Patrick P. Chen (Division for Statistical and Data Sciences, RTI International, Research Triangle Park, NC) for helping with the statistical analysis.

\section{Funding}

This work was supported by the NSF BREAD program [IOS0965429]; JW wishes to thank the National Natural Science Foundation of China for providing funding [No. 31501619].

\section{References}

Bozkurt TO, Schornack S, Win J, Shindo T, Ilyas M, Oliva R, Cano LM, Jones AME, Huitema E, Van Der Hoorn RAL, Kamoun S. 2011. Phytophthora infestans effector AVRblb2 prevents secretion of a plant immune protease at the haustorial interface. Proc Natl Acad Sci USA. 108:20832-20837.

Büschges R, Hollricher $\mathrm{K}$, Panstruga R, Simons $\mathrm{G}$, Wolter $\mathrm{M}$, Frijters A, vanDaelen R, vanderLee T, Diergaarde P, Groenendijk J, et al. 1997. The barley mlo gene: A novel control element of plant pathogen resistance. Cell. 88:695-705.

Campbell J, Zhang H, Giroux MJ, Feiz L, Jin Y, Wang M, Chen X, Huang L. 2012. A mutagenesis-derived broad-spectrum disease resistance locus in wheat. Theor Appl Gen. 125:391-404.

Dietrich RA, Delaney TP, Uknes SJ, Ward ER, Ryals JA, Dangl JL. 1994. Arabidopsis mutants simulating disease resistance response. Cell. 77:565-577.

Dietrich RA, Richberg MH, Schmidt R, Dean C, Dangl JL. 1997. A novel zinc finger protein is encoded by the Arabidopsis LSD1 gene and functions as a negative regulator of plant cell death. Cell. 88:685-694.

Dodds PN, Lawrence GJ, Catanzariti AM, Ayliffe MA, Ellis JG. 2004. The Melampsora lini AvrL567 avirulence genes are expressed in haustoria and their products are recognized inside plant cells. Plant Cell. 16:755-768.

Feiz L, Beecher BS, Martin JM, Giroux MJ. 2009. In planta mutagenesis determines the functional regions of the wheat puroindoline proteins. Genetics. 183:853-860.

Frye CA, Tang DZ, Innes RW. 2001. Negative regulation of defense responses in plants by a conserved MAPKK kinase. Proc Natl Acad Sci USA. 98:373-378.

Gray J, Close PS, Briggs SP, Johal GS. 1997. A novel suppressor of cell death in plants encoded by the Lls1 gene of maize. Cell. 89:25-31.

Hall JL, Williams LE. 2000. Assimilate transport and partitioning in fungal biotrophic interactions. Aust J Plant Physiol. 27:549-560.

Huckelhoven R. 2005. Powdery mildew susceptibility and biotrophic infection strategies. FEMS Microbiol Lett. 245:9-17.

Klement Z. 1963. Rapid detection of the pathogenicity of phytopathogenic pseudomonads. Nature. 199:299-300.

Klement Z, Goodman RN. 1967. Role of living bacterial cell and induction time in hypersensitive reaction of tobacco plant. Phytopathology. 57:322.

Long DL, Kolmer JA. 1989. A North American system of nomenclature for Puccinia recondita f. sp tritici. Phytopathology. 79:525-529.

Luna E, Pastor V, Robert J, Flors V, Mauch-Mani B, Ton J. 2011. Callose deposition: a multifaceted plant defense response. Mol PlantMicrobe Interact. 24:183-193.

Lyngkjaer MF, Jensen HP, Østergård H. 1995. A Japanese powdery mildew isolate with exceptionally large infection efficiency on Mloresistant barley. Plant Pathol. 44:786-790. 
McIntosh RA, Wellings CR, Park RF. 1995. Wheat rusts: an atlas of resistance genes. London: CSIRO.

Mendgen K, Hahn M. 2002. Plant infection and the establishment of fungal biotrophy. Trends Plant Sci. 7:352-356.

Niks RE. 1983. Haustorium formation by Puccinia hordei in leaves of hypersensitive, partially resistant, and non-host plant genotypes. Phytopathology. 73:64-66.

Niks RE. 1986. Failure of haustorial development as a factor in slow growth and development of Puccinia hordei in partially resistant barley seedlings. Physiol Mol Plant Pathol. 28:309-322.

Rubiales D, Niks RE. 1995. Characterization of Lr34, a major gene conferring nonhypersensitive resistance to wheat leaf rust. Plant Dis. 79:1208-1212.

Shipton WA, Brown JF. 1962. A whole-leaf clearing and staining technique to demonstrate host-pathogen relationships of wheat stem rust. Phytopathology. 52:1313.
Shirasu K, Schulze-Lefert P. 2000. Regulators of cell death in disease resistance. Plant Mol Biol. 44:371-385.

Stakman EC. 1915. Relation between Puccinia graminis and plants highly resistant to its attack. J Agric Res. 4:193-199.

Tennant JR. 1964. Evaluation of the trypan blue technique for determination of cell viability. Transplantation. 2:685-694.

Voegele RT, Mendgen K. 2003. Rust haustoria: Nutrient uptake and beyond. New Phytol. 159:93-100.

Wang X, Wang X, Duan Y, Yin S, Zhang H, Huang L, Kang Z. 2013. $T a A b c 1$, a member of $A b c 1$-like family involved in hypersensitive response against the stripe rust fungal pathogen in wheat. PLoS One. 8: e58969.

Wolter M, Hollricher K, Salamini F, Schulze-Lefert P. 1993. The mlo resistance alleles to powdery mildew infection in barley trigger a developmentally controlled defense mimic phenotype. Mol Gen Genet. 239:122-128. 